\title{
A New Tool For The Hygrothermal Simulation Of Building Components: ProCasaClima Hygrothermal
}

\author{
Marco Larcher ${ }^{1}$, Martina Demattio ${ }^{2}$, Alexandra Troi ${ }^{2}$ \\ ${ }^{1}$ Eurac Research, Bolzano, Italy \\ ${ }^{2}$ Agency for Energy South Tyrol - KlimaHaus/CasaClima, Bolzano, Italy
}

\begin{abstract}
This paper presents a new tool for the simulation of the combined transport of moisture and heat in building components. The tool, called ProCasaClima Hygrothermal, is more advanced with respect to the hygrothermal assessment methods based on the Glaser approach since it provides the possibility to perform dynamical simulations and because it takes into account capillary liquid transport and moisture storage properties of materials. ProCasaClima Hygrothermal aims to be user-friendly and easy to use in order to maximize its use among designers and consultants. The tool is partly presented through an analysis of a case study project, an historical building where the external walls are insulated from the inside with a vapour open insulation system. The hygrothermal performance of the historical wall are also monitored, giving the possibility to compare the results of the simulation with monitored data.
\end{abstract}

\section{Introduction}

During the last few decades there has been a growing activity in the development of numerical tools for the simulation of the coupled transport of heat and moisture in building constructions (Delgado et al., 2013). The main reason behind that is the prevention of building pathologies, that can lead to the degradation of building components and affect users' comfort and health.

Nonetheless, the usage of these simulation tools among designers in the everyday design practice is still limited. This might represent a problem considering that the number of energy-efficient interventions on existing buildings is expected to grow in future years (ANCE, 2018; Directive 2018/844/EU, 2018) and will increasingly involve buildings with major design challenges from the hygrothermal point of view such as building of historical value with protected facades or with thermal bridges of difficult solution (Troi, 2011). Design solutions such as internal insulation will become more and more widespread making the use of advanced simulation tools essential. In fact, the application of internal insulation strongly modifies the hygrothermal equilibrium of the existing wall and a careful planning is needed in order to avoid problems such as interstitial condensation, frost damages, thermal bridges and mould formation (Troi and Bastian, 2015; Zhao et al., 2017).

It is therefore of fundamental importance to encourage the use of dynamical hygrothermal simulations among designers by proposing user-friendly design tools. At the Italian level the Klimahaus Agency of Bolzano with the support of Eurac Research is pushing in this direction with the creation of a new extension of the ProCasaClima software (Rondoni et al., 2015) dedicated to the simulation of the combined transport of heat and moisture in building components.

The aim of this paper is to present this new tool called ProCasaClima Hygrothermal and to show its application to a real case study project where a comparison with monitored data is also performed.

\section{ProCasaClima Hygrothermal: the concept}

ProCasaClima Hygrothermal is developed within the ERDF European project BuildDOP as part of the next generation of the ProCasaClima software, which will upgrade ProCasaClima from a certification tool of building energy performance into a full design instrument. ProCasaClima Hygrothermal will be distributed free of charge by the Klimahaus Agency of Bolzano.

The main concept behind ProCasaClima Hygrothermal is to provide a tool that goes beyond the traditional hygrothermal assessment methods based on the Glaser approach (EN ISO 13788, 2012) but easier to use and more user-friendly than the dynamic simulation software most popular nowadays among designers, i.e. WUFI and DELPHIN. The software is formed by an Excel GUI, used to define the input and evaluate the output of the simulations, and by an external solver, which is run through the GUI and that provides the actual solution of the physical equations. The external solver is the same that is used within the software DELPHIN and it represents a high-performance solver validated according to the EN 15026.

Similarly, to established hygrothermal simulation tool, such as WUFI and DELPHIN, ProCasaClima Hygrothermal is capable of describing the following physical phenomena: heat storage, heat conduction, moisture storage, capillary liquid convective transport and vapour diffusion. It is a dynamical simulation tool that can deal with hourly boundary conditions and that can take into considerations the following climatic phenomena: internal and external temperature, internal and external relative humidity, solar radiation and driving rain.

The main advantages of ProCasaClima Hygrothermal with respect to methods based on the Glaser approach are 
the following: 1) capillary liquid transport is taken into account 2) hygroscopic storage properties are considered 3) physical properties of building materials changes as a function of the moisture content 4) it considers hourly weather files 5) It includes the effect of radiation and driving rain. These limitations of the Glaser approach can lead to wrong evaluations of specific design solutions whenever the above-mentioned effects cannot be neglected. A typical example is internal insulation of walls with capillary active insulation systems, a design approach whose working mechanism is based on the capillary liquid transport properties of insulating materials (Zhao et al., 2017). In this situation the Glaser approach tends to exclude design variants that are safe from the hygrothermal point of view (Ruisinger and Grunewald, 2009) leading to wrong design choices.

ProCasaClima Hygrothermal is specifically designed to be accessible to a large number of practitioners including architects, engineers and building surveyors. Several aspects have been considered to make the tool user friendly and easy to use. Firstly, the Excel GUI is a working environment that most of the designers are familiar with. Secondly, the input of the necessary data for the simulation is guided and the use of drop-down menus help designers selecting the correct parameters. The parameters that can be varied by the user are selected carefully, finding a trade-off between flexibility and simplicity. Finally, the relevant outputs needed for the evaluation of the hygrothermal performances of the building component are predefined and associated with clear evaluation criteria, to support designers in the interpretation of the obtained results.

ProCasaClima Hygrothermal can be used to simulate 1D building components and it can be applied to vertical walls as well as to inclined or horizontal construction elements. Its main application will be the evaluation of moisture related damages in internally insulated walls or flat roofs. These are the two type of constructions that are most frequently studied with hygrothermal simulation tools. Evaluation of 2D complex construction details is still not possible with ProCasaClima Hygrothermal. Also the simulation of energy or moisture sources is currently not possible with ProCasaClima Hygrothremal. Therefore the simulation of phenomena such as the effect of radiant heating system or external water infiltration cannot be performed.

A detailed description of the tool will be given in the next sections by showing its application to a real case study.

\section{Application to a real case study}

The case study building is located in the municipality of Terlano, a few kilometres from Bolzano. The location has the same altitude of Bolzano and very similar climatic conditions.

The building is a rural house from the seventeenth century, which is currently used as a single-family house. The relevant construction element for the present paper is the external wall and more precisely the north-east facing wall (azimuth: $62^{\circ}$ from the North). The historical wall is made of a local stone with lime mortar joints and has a consistent thickness of about $44 \mathrm{~cm}$. It is plastered on both sides with lime plaster. In 2017 the whole building was refurbished. In particular, the north-east wall was insulated from the inside with $8 \mathrm{~cm}$ of wood fibre. The insulation boards were attached to the existing interior plaster by means of a clay adhesive mortar that was applied directly on the existing interior plaster. Also, the existing historical exterior plaster was kept in place, but it was covered with a new lime plaster in order to fill some cracks and some spots where the historical plaster was disrupted. The same lime plaster was used also on the interior side of the wall as finishing layer. A diagram of the wall build-up is sketched in the upper part of Figure 3.

\section{Methodology}

The internally insulated wall of the case study under consideration is analysed with ProCasaClima Hygrothermal and the results are compared with those obtained from a monitoring system. Moreover, for comparison, the construction is also analysed with the UNI EN ISO 13788 assessment method, a stationary monthly calculation based on the Glaser approach.

\section{UNI EN ISO 13788 evaluation}

The calculation according to the UNI EN ISO 13788 standard is performed considering the climate of Bolzano. The external monthly data are taken from the UNI 10349 standard while the internal boundary conditions are calculated following the prescriptions given in the National Appendix of the UNI EN ISO 13788 standard. In particular, the internal relative humidity is calculated using the model for maritime climates and applying moisture class 3: "Buildings with unknown occupancy".

\section{ProCasaClima Hygrothermal simulation}

In this subsection the methodology that is applied for the hygrothermal simulation is presented. This provides also the opportunity to describe the parameters that can be set in ProCasaClima Hygrothermal and those that have predefined values.

The material database of ProCasaClima Hygrothermal is, at present, the same of the software DELPHIN. In future it is planned to extend this database with focus on Italian materials, both in terms of products and in terms of existing building materials. For the simulation presented in this paper, the materials are all chosen from the tool database. For some materials, such as the wood fibre insulation, the database contains exactly the same product that is installed in the real case study project, for some other materials this is not the case. In such cases a material which is as close as possible to the one installed on site is selected. The selection is done mainly according to the material description and trying to match the available hygrothermal properties taken form the technical datasheet (such as bulk density, thermal conductivity or vapour diffusion resistance factor). In case the selected material has some properties that differ slightly from those of the datasheet, they are changed accordingly and the corresponding hygrothermal function are rescaled. The layer of the historical wall, composed by mortar joints and stones, is approximated with a unique $1 \mathrm{D}$ stone 
layer, since it was shown that this has a limited effect on dynamical simulations when dealing with vapour open insulations systems (Bottino et al. 2018; Vereecken and Roels, 2013). The basic hygrothermal properties of the materials employed in the hygrothermal simulation are reported in Table 1.

Table 1: Basic hygrothermal properties of the materials used for the hygrothermal assessment. The identification number (ID) used in the table is the same that is used in

Figure 3. The other parameters shown in the columns are: bulk density $(\rho)$, specific heat capacity $\left(c_{p}\right)$, thermal conductivity $(\lambda)$, vapour diffusion resistance factor $(\mu)$, water uptake coefficient $\left(A_{w}\right)$.

\begin{tabular}{|c|c|c|c|c|c|c|}
\hline ID & Material & $\begin{array}{c}\rho \\
{\left[\boldsymbol{K g} / \mathbf{m}^{3}\right]}\end{array}$ & $\begin{array}{c}\boldsymbol{c}_{\boldsymbol{p}} \\
{[\mathbf{K} \boldsymbol{K} \boldsymbol{K}]}\end{array}$ & $\begin{array}{c}\boldsymbol{\lambda} \\
{[\boldsymbol{W} / \mathbf{m} \boldsymbol{K}]}\end{array}$ & $\begin{array}{c}\boldsymbol{\mu} \\
{[-]}\end{array}$ & $\begin{array}{c}\boldsymbol{A}_{\boldsymbol{w}} \\
{[\boldsymbol{k g} / \boldsymbol{m} \sqrt{s}]}\end{array}$ \\
\hline 1 & Lime plaster & 1200 & 830 & 0.57 & 12.5 & 0.208 \\
\hline 2 & $\begin{array}{c}\text { Wood fibre } \\
\text { insulation }\end{array}$ & 150 & 2000 & 0.042 & 3 & 0.082 \\
\hline 3 & $\begin{array}{c}\text { Clay adhesive } \\
\text { mortar }\end{array}$ & 2650 & 1050 & 1 & 10 & 0.045 \\
\hline 4 & $\begin{array}{c}\text { Historical lime } \\
\text { plaster }\end{array}$ & 1800 & 850 & 0.82 & 12 & 0.249 \\
\hline 6 & Stone/ Granite & 2453 & 702 & 1.718 & 53.8 & 0.015 \\
\hline
\end{tabular}

The ProCasaClima Hygrothermal climate database is based on the Italian climate datasets developed in 2016 by the CTI (Murano et al., 2016). They contain hourly data of temperature, relative humidity, global/diffuse horizontal radiation and wind speed in the form of TMYs calculated according to the EN ISO 15927-4 standard. Unluckily these datasets do not contain rain and wind direction data, and they cannot be used to simulate the effect of wind driven rain on the façade. The climate data are available for every Italian province for a total of 110 datasets. In addition to the internal database, in ProCasaClima Hygrothermal, it is possible to import external climate datasets using csv files with a specific header. These data can include also rain and wind data and, in this case, the effect of driving rain is simulated by ProCasaClima Hygrothermal. In particular, driving rain is calculated starting from horizontal rain and wind data according to the model presented in the EN ISO 15927-3 standard. For the specific case study under consideration the climate dataset is chosen from the internal database and, in particular, the province of Bolzano is selected. The effect of the driving rain is therefore neglected, but, for this specific building, the simplification has a minor effect due to the rain protection provided by a long roof overhang.

The interior climate in ProCasaClima Hygrothermal consists in hourly data of temperature and relative humidity. It can be calculated according to two adaptive interior climate models that are derived from the standard EN 15026 and EN ISO 13788. In both models, the internal temperature is calculated from the external temperature according to the two graphs presented in the upper part of Figure 1. In particular the top left graph relates to the EN 15026 model and the top right graph to the EN ISO 13788 model. As regards the internal relative humidity, for the EN 15026 model it is directly derived from the external temperature according to the bottom left graph presented in Figure 1. Two different moisture classes can be selected depending on the moisture sources of the building. For the EN ISO 13788 model the internal absolute humidity, $v_{i}$, is derived from the external absolute humidity, $v_{e}$, with an added moisture supply that takes into account the internal humidity sources of the building, $\Delta v$ :

$$
v_{i}=v_{e}+\Delta v
$$

The value of, $\Delta v$, depends on the external temperature and on the type of building, in fact five different moisture classes can be selected. The values of $\Delta v$ for the five moisture classes are presented in the bottom right graph in Figure 1. In the simulation presented in this paper the EN 15026 model is used and moisture class A is selected. This correspond to a buildings with normal occupancy and leads to an internal temperature ranging between $20^{\circ} \mathrm{C}$ and $25^{\circ} \mathrm{C}$, and an internal relative humidity varying between $30 \%$ and $60 \%$.
EN 15026 Model
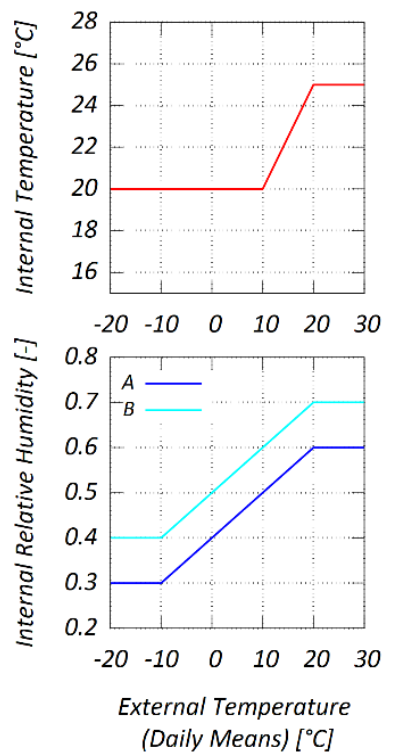

EN ISO 13788 Model
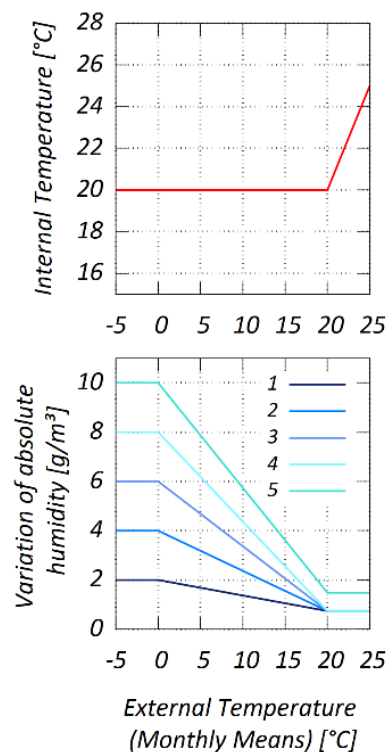

Figure 1: Description of the adaptive models for the calculation of the interior climate of the building. The models are derived from the standard EN 15026 (left)

and EN ISO 13788 (right). (Top panels) Interior temperature of the building as a function of the exterior temperature. (Bottom left panel) Interior relative

humidity of the building as a function of the external temperature for two different moisture classes. (Bottom right panel) Variation of absolute humidity, $\Delta v$, between interior and exterior climate as a function of the external temperature and for five moisture classes.

The heat and vapour exchange coefficients in ProCasaClima Hygrothermal have predefined values that are taken from the standards EN ISO 6946 and EN 15026. The user has just to select the type of construction under analysis (vertical wall, roof, horizontal floor slab), its inclination and orientation. A vertical wall is considered in the case study analysed in the present paper. Therefore, the heat conduction exchange coefficient of the exterior surface is set to $25 \mathrm{~W} / \mathrm{m}^{2} \mathrm{~K}$, while the vapour diffusion 
coefficient is set to $8.034 \times 10^{-8} \mathrm{~s} / \mathrm{m}$. For the interior surface instead, the heat transfer coefficient is set to $7.64 \mathrm{~W} / \mathrm{m}^{2} \mathrm{~K}$, while the value of the vapour diffusion coefficient is set to $2.42 \times 10^{-8} \mathrm{~s} / \mathrm{m}$. Other parameters that should be selected in ProCasaClima Hygrothermal are the absorption coefficient for short wave radiation of the external surface, $\alpha$, and the shading factor,$s$, that represents the fraction of solar radiation that reaches the simulated building component while the remaining part is blocked by the surrounding shading elements. For the case study under consideration the following values are chosen: $\alpha=0.7$ and $s=0.4$.

The numerical calculation in ProCasaClima Hygrothermal always begins the $1^{\text {st }}$ of October to simulate a worst-case scenario with the critical combination of built-in moisture and moisture input via diffusion in the winter period (W.T.A. Merkblatt 6-5, 2014). Also, the initial hygrothermal conditions of the construction have predefined values in ProCasaClima Hygrothermal: the wall is initially assumed to be in equilibrium in an environment with a temperature of $20^{\circ} \mathrm{C}$ and a relative humidity of $80 \%$.

Finally, we would like to stress that the selection of the input parameters for the simulation presented in this paper was done with the information that typically a designer has when setting up a hygrothermal simulation. Therefore, no information obtained from the monitored data is used to select or calibrate the parameters of the model.

\section{The monitoring system}

The monitoring system is installed in the case study building with the aim of analysing the temperature and relative humidity profile within the wall. Therefore, combined temperature and relative humidity sensors are installed at the interfaces between the different materials composing the wall. The exact positions where the sensors were placed are indicated by the red arrows in Figure 2Figure 3. The sensors combine an NTC thermistor and a capacitive humidity sensor with an accuracy of $\pm 0.3^{\circ} \mathrm{C}$ and $\pm 2.5 \%$ respectively. In addition, the climatic boundary conditions are measured both inside and outside the building. Inside the building temperature and relative humidity of the room are measured, outside the building the following parameters are measured: ambient temperature, surface temperature, ambient relative humidity, global radiation on the wall surface and driving rain on the wall surface. The sun radiation is measured with a second class pyranometer directly placed on the external façade of the monitored wall. The driving rain is measured by means of a tipping bucket rain gauge combined with an aluminium plate placed on the wall that collects the rain impinging on the façade. The monitoring period presented in this paper starts the $1^{\text {st }}$ of February 2018 and ends the $18^{\text {th }}$ of December 2018.

\section{Results and discussion}

The hygrothermal assessment performed according to the UNI EN ISO 13788 standard results in an excessive hygrothermal risk. Condensation takes place at the interface between the insulation and the adhesive mortar. In particular, the condensation period starts in December and finishes in February with a total condensation accumulation of $519.5 \mathrm{~g} / \mathrm{m}^{2}$. The condensate then evaporates completely during the summer period but the critical threshold of $500 \mathrm{~g} / \mathrm{m}^{2}$ recommended by the UNI EN ISO 13788 standard is exceeded.

However, the Glaser based approaches are known to be not accurate especially when dealing with vapour open insulation systems that involve materials with nonnegligible capillary liquid conductivity (Ruisinger and Grunewald, 2009). In particular, the main limitations of this approach in the context of this building are the fact capillary liquid transport is neglected and that the hygroscopic storage properties are not taken into account. The hygrothermal dynamical simulation performed with ProCasaClima Hygrothermal as well as the analysis of the monitoring data provide a more accurate analysis of the construction under consideration.

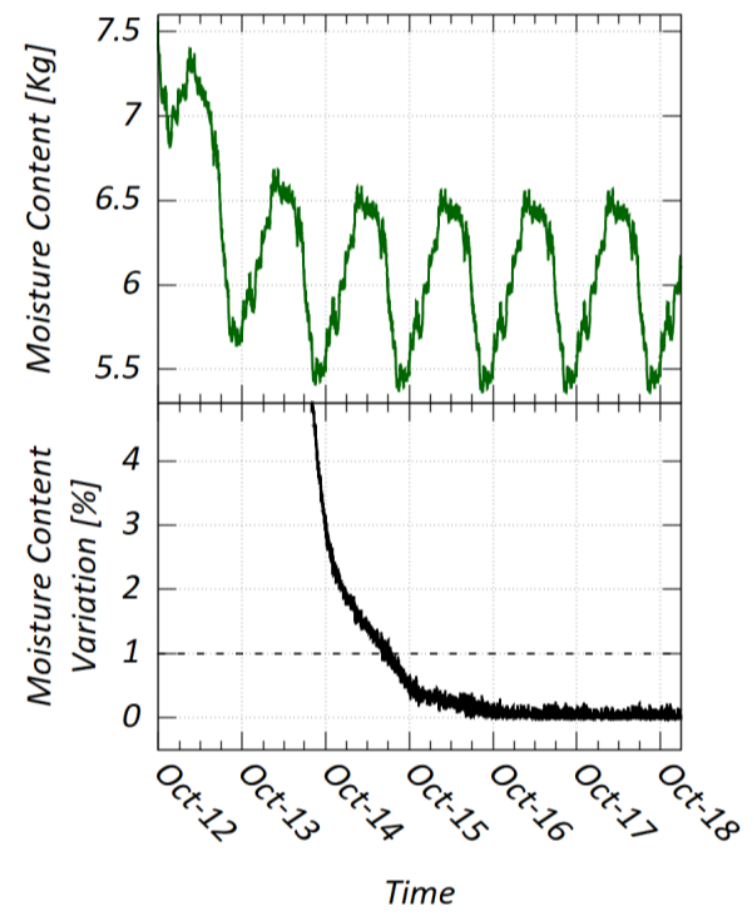

Figure 2: Time evolution of the total integrated moisture content of the wall build-up (top panel). Variation of the moisture content with respect to the previous simulation year as a function of time (bottom panel).

The first output that it is analysed with ProCasaClima Hygrothermal is the total moisture content, $w_{T}(t)$, i.e. the total amount of moisture accumulated in all the materials of the wall build up. This parameter is shown in the upper part of Figure 2 as a function of time. It is possible to observe that the total moisture content decreases in the first simulation years and then, after the third year, its behaviour becomes periodic. This last statement is even more clear looking at the bottom part of Figure 2 where the percentage variation of the total moisture content with respect to the previous year is shown. More precisely this parameter is defined as follows 


$$
\Delta w_{T}(t)=\frac{\left|w_{T}(t)-w_{T}\left(t-T_{\text {year }}\right)\right|}{w_{T}\left(t-T_{\text {year }}\right)}
$$

where $T_{\text {year }}$ is the time span corresponding to one year. $\Delta w_{T}(t)$ is defined only for $t \geq T_{\text {year }}$. The lower part of Figure 2 shows that after the $4^{\text {th }}$ year $\Delta w(t)$ becomes smaller than $1 \%$ indicating that the simulation is long enough (W.T.A. Merkblatt 6-5, 2014).
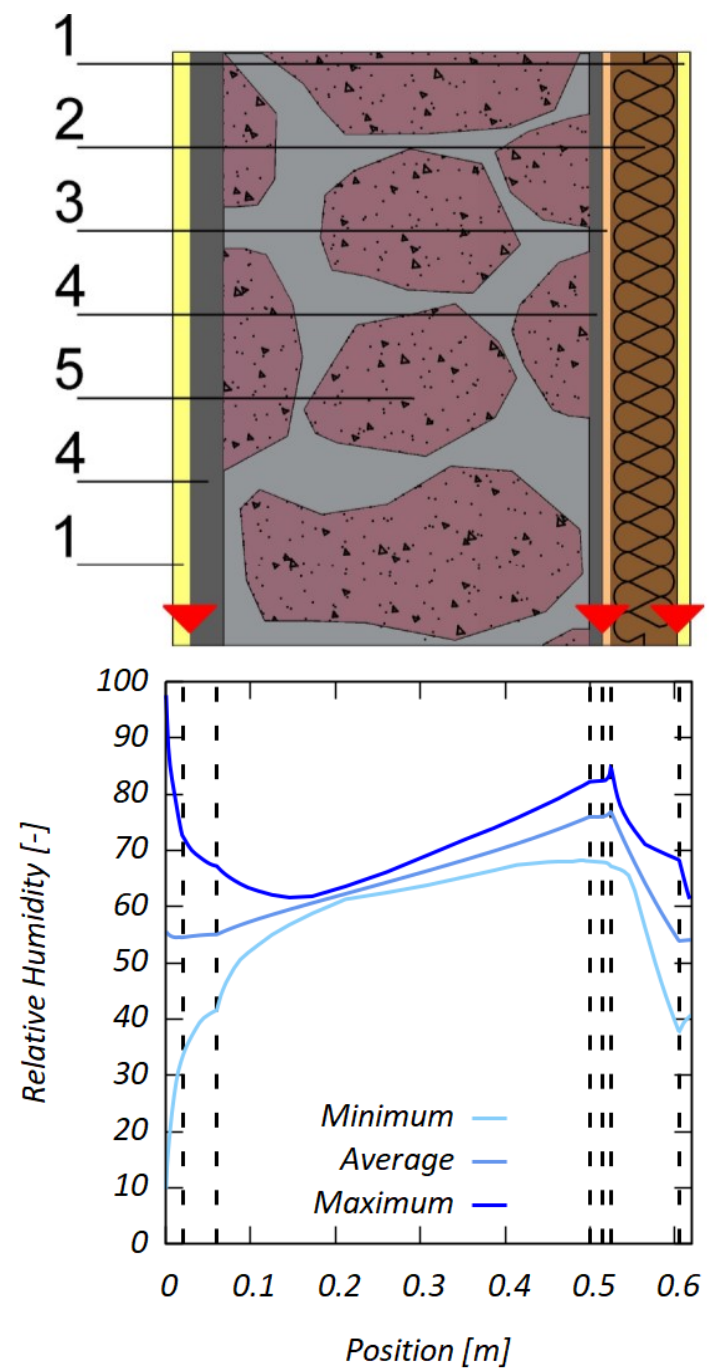

Figure 3: (Top panel) Graphical representation of the wall build-up after the retrofit intervention. The numbers in the left part of the figure identify the different materials: 1. new lime-based plaster 2. wood fibre insulation 3. clay adhesive mortar 4. historical lime plaster 5. existing stone wall. The red arrows indicate the position of the combined temperature and relative

humidity sensors installed on site (Bottom Panel)

Maximum, average and minimum relative humidity profiles obtained in the last simulation year. The vertical dashed lines represent the interfaces between different materials.

The second relevant output of the ProCasaClima Hygrothermal simulation is shown in the bottom part of Figure 3. The maximum, the average and the minimum relative humidity profiles in the wall build up are plotted for the last simulation year. One can observe that the most critical point from the hygrothermal point of view is the cold side of the insulation. In fact, there the highest relative humidity is reached. (a higher maximum relative humidity is reached in the outer layers of the wall, nevertheless this is simply due to a high external ambient relative humidity and should not be considered a critical hygrothermal behaviour). This confirms what was already observed with the UNI EN ISO 13788 approach.

Therefore, the cold side of the insulation is analysed more carefully. In particular, the interface between the adhesive mortar and the existing lime plaster is considered since this is also the location where the combined temperature and relative humidity sensor was positioned. Figure 4 shows the temperature and the relative humidity as a function of time for one simulation year (solid lines with lighter colours) when the periodic behaviour is already reached. The temperature behind the insulation varies between $3{ }^{\circ} \mathrm{C}$ and $27^{\circ} \mathrm{C}$ and the relative humidity between $67 \%$ and $82 \%$, excluding the occurrence of frost damages in this area as well as the formation of interstitial condensation. In fact, the relative humidity is below 95\% that is typically identified as the critical value for the appearance of free water in the construction that can give rise to moisture related damages (W.T.A. Merkblatt 6-5, 2014).

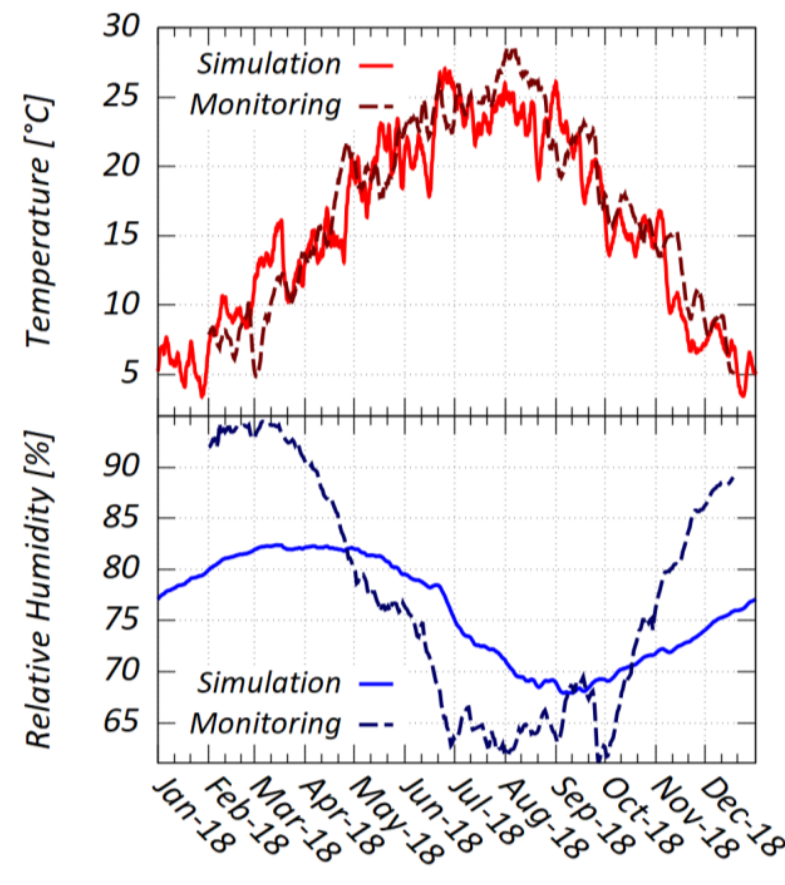

Time

Figure 4: Time evolution of the temperature behind the insulation (top panel) and of the relative humidity

behind the insulation of the monitored and simulated data.

In Figure 4 the temperature and relative humidity data monitored at the interface between the adhesive mortar and the existing lime plaster are also show (dashed lines with darker colours). It can be observed that the monitored and simulated temperature data have a similar behaviour. Clearly the local details of the curves are different since the simulation is based on a typical year and not on the 
real monitored boundary conditions. Anyway, the overall evolution is very similar. The most significant difference between the two datasets occurs in the summer period, where the monitored temperatures reaches values around $29^{\circ} \mathrm{C}$ while the simulated temperatures have a maximum of about $27^{\circ} \mathrm{C}$. This difference is due to the fact that the internal climate in the simulation is calculated according to the adaptive climate model of the standard EN 15026. This model limits the internal temperature between $20^{\circ} \mathrm{C}$ and $25^{\circ} \mathrm{C}$. However, the monitored building does not have an active cooling system and therefore in summer internal temperatures can exceed the $25^{\circ} \mathrm{C}$ limit. This results in higher temperatures also in the layer behind the insulation.

The lower part of Figure 4 shows that the simulated and monitored relative humidities have the same overall trend. In both cases the relative humidity grows in winter due the fact that the vapour produced in the building reaches the cold spot behind the insulation. In summer the vapour reevaporates to the interior side of the building leading to a decrease of the relative humidity behind the insulation. This is a typical behaviour in vapour open insulation systems. However, the details of the two curves are quite different. In the monitored dataset the range of variation is larger: the maximum monitored relative humidity is $95 \%$ while the minimum one is $60 \%$. Moreover, the drying and the wetting processes that occur at the beginning of the warm period and at the beginning of the cold period, respectively, are faster in the monitored data. A possible interpretation for the lower relative humidity in summer is related again to the internal climate model used in the simulation. As previously mentioned, this model underestimates the internal temperatures in summer (Kalamees et al., 2006). Moreover, it overestimates the internal relative humidity leading to a slower drying and therefore to the observed discrepancy.

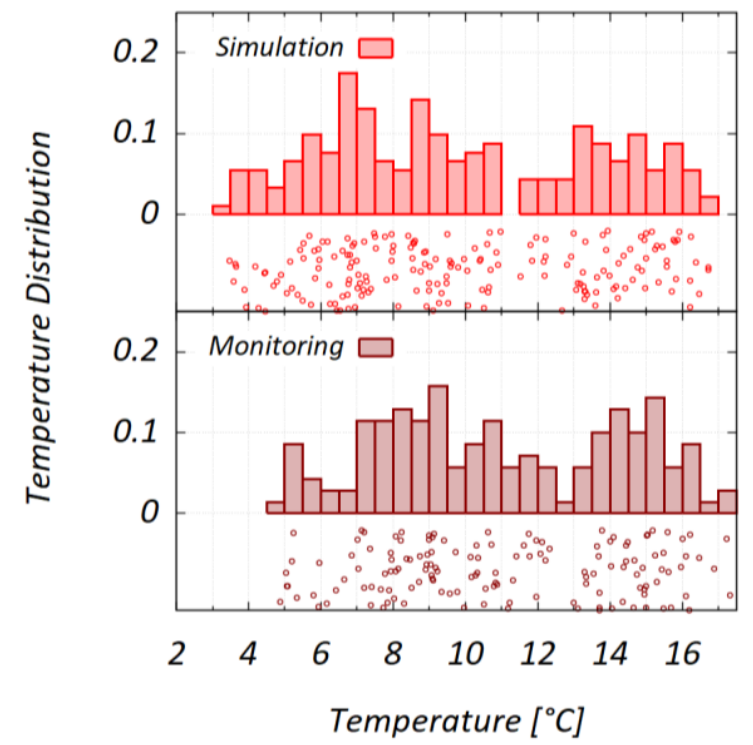

Figure 5: Histogram representing the distribution of the daily average temperatures behind the insulation during the heating period for the simulated data (top panel) and the monitored data (bottom panel).
In order to summarize the comparison between simulated and monitored data, the mean error for the temperature and relative humidity data is reported for the heating period and for the non-heating period. In particular, the mean error for temperature is $-0.2{ }^{\circ} \mathrm{C}$ during the heating period and $1.0^{\circ} \mathrm{C}$ during the non-heating period. The mean error for relative humidity is $9.8 \%$ during the heating period and $-4.6 \%$ during the non-heating period. The heating period is defined according to the Italian standard UNI/TS 11300-1 and it runs from October 15 to April 15 for the specific climate zone of Bolzano.

As regard the heating period, a more detailed analysis of the monitored and simulated hygrothermal parameters behind the insulation is shown in Figure 5 and Figure 6 . This detailed analysis is limited to the heating period since it is the most critical for the occurrence of moisture related damages. In particular, Figure 5 shows a histogram of the average daily temperatures observed during the heating period for the simulated (top panel) and for the monitored data (bottom panel). Figure 5 confirms that the two temperatures distributions are very similar. The simulation shows lower temperatures but this might be due to the fact that the monitored data are currently not present for the coldest period of the year (last part of December and January).

Figure 6 shows the same output of Figure 5 but for the relative humidity.

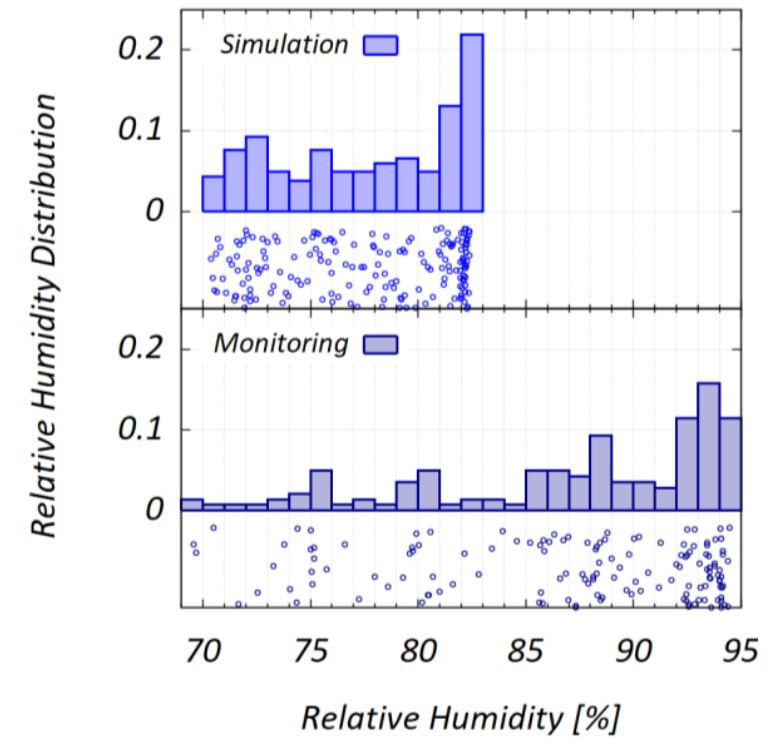

Figure 6: Histogram representing the distribution of the daily average temperatures behind the insulation during the heating period for the simulated data (top panel) and the monitored data (bottom panel).

Figure 6 clearly indicates that in the monitored data higher relative humidities are observed during the heating period, leading to an increased hygrothermal risk with respect to what is indicated by the simulation. Two possible causes are identified in order to explain the observed discrepancy:

- Materials built in moisture

- Convective air flows 
The insulation system was installed at the end of August 2017 by using a wet adhesive mortar, having therefore an initial bult-in moisture content corresponding to a relative humidity of $100 \%$. It is reasonable to assume that this initial moiusture content has an influence on the monitored relative humidity, especially in the first months of 2018, that is when the highest relative humidities are measured. In ProCasaClima Hygrothermal a standardardized initial relative humidity of $80 \%$ is assumed by default for all the materials and it cannot be changed by the user. This choice is done in order to simplify the GUI of the tool and to reduce the numbers of input, making the tool more user friendly. Moreover, the tool is designed especially to evaluate the simulated constructions in the periodic part of the simulation and not during the transient periods. Anyway, this could be an oversimplified assumption if one wants to evaluate transient phenomena.

The phenomenon of convective air transport is not included in ProCasaClima Hygrothermal. In constructions where the airtight layer is not designed and implemented properly this can lead to inaccurate results, in fact it is known that convective air transport has a dramatic influence in the moisture balance of constructions (Troi and Bastian, 2015; Havinga and Schellen, 2018). In the specific case study under evaluation, it was observed that during the construction stage, there was no strong emphasis put on the airtightness of the building and therefore it is reasonable to assume that this might play a significant role in the hygrothermal behaviour of the wall build up. In general, the occurrence of convective moisture transport must be avoided in constructions, especially when dealing with internal insulation solutions. For this reason, ProCasaClima Hygrothermal was designed assuming that convective moisture transport can be neglected thanks to the presence of an airtight layer that prevents the occurrence of this phenomenon. It is therefore important to consider that the ProCasaClima Hygrothermal provides realistic results only under these conditions.

In other simulation software, such as WUFI or DELPHIN, the effect of a faulty airtightness layer can be simulated with an approximated model by means of an additional moisture source. It will be evaluated whether to include this option also in ProCasaClima Hygrothermal. However, having the possibility of simulating convective air flows should not lead to the design choice of not planning a continuous and uninterrupted airtight layer. From our point of view the simulation of convective air flows should only be used to evaluate the robustness of a design choice in relation to a wrong implementation of the airtight layer on site, that should preferably be avoided.

\section{Conclusion}

This paper has presented ProCasaClima Hygrothermal, a dynamical simulation tool for the hygrothermal modelling of one-dimensional building components.

The tool has been applied to a real case study building, an historical rural house where the external walls have been insulated from the inside with wood fibre insulation panels.

The hygrothermal behaviour of the wall has been also monitored by placing combined temperature and relative humidity sensors within the construction. A comparison of the results of the simulation with the monitored data has shown a very good agreement when considering thermal parameters. When considering hygrometric parameters, a similar qualitative behaviour has been observed, but from the quantitative point of view a deviation has been observed. Three possible causes have been identified as possible sources of error. Firstly, it has been observed that the simulation of the interior climate with the simplified adaptive model of the standard EN 15026 does not always provide realistic results. Secondly, the initial conditions of the simulation are unrealistic. Built in moisture in materials is not considered in the simulation tool and this can be a second cause of discrepancy. Thirdly the fact that in the tool convective air transport is neglected can lead to an underestimation of the hygrothermal risk especially in buildings where the airtightness layer has not been implemented properly.

A possible development of the analysis presented in this paper is to increase the agreement between the simulation results and the monitoring data by means of a calibration procedure. An effective strategy to reach this goal is the use of optimization tools (Roberti et al., 2015; Freudenberg et al., 2017). This approach would require the use of more advanced hygrothermal simulation that allow to use user-defined boundary conditions, that have the possibility to simulate built-in moisture and that can describe the effect of convective airflows, as for instance DELPHIN. This approach would give the possibility to identify the correct parameters of the hygrothermal model and, therefore, it could be used to check the correctness of the hypothesis above on the main sources of error of the numerical simulation. This information could then be used to further improve ProCasaClima Hygrothermal.

\section{Acknowledgement}

The research leading to these results has received funding from the European Regional Development Fund (ERDF) within the project BuildDOP "Evaluation tool to ensure best building performance from design to operation" (project no. FESR1022).

\section{References}

ANCE, Associazione Nazionale Costruttori Edili (2018), Osservatorio Congiunturale sull'Industria delle Costruzioni.

Bottino, D., Larcher, M., Troi, A., Grunewald, J. (2018), Hygrothermal performance of historic massive wall: when is 2D simulation necessary?, Proceedings from IBPC2018: 7th International Building Physics Conference, 23-26 September 2018.

Delgado, J.,Barreira, E., Ramos, N., Peixoto de Freitas, V. (2013). Hygrothermal Numerical Simulation Tools Applied to Building Physics. Springer. 
Ente Italiano di Normazione (2013). Prestazione igrotermica dei componenti e degli elementi per edilizia - Temperatura superficiale interna per evitare l'umiditá superficiale critica e la condensazione interstiziale - Metodi di calcolo (UNI EN ISO 13788).

Ente Italiano di Normazione (2014). Prestazioni energetiche degli edifici - Parte 1: Determinazione del fabbisogno di energia termica dell'edificio per la climatizzazione estiva ed invernale (UNI/TS 11300-1).

Ente Italiano di Normazione (2016). Riscaldamento e raffrescamento degli edifici - Dati climatici - Parte 1: Medie mensili per la valutazione della prestazione termo-energetica dell'edificio e metodi per ripartire l'irradianza solare nella frazione diretta e diffusa e per calcolare l'irradianza solare su di una superficie inclinata (UNI 10349-1).

European Commitee for Standardisation (2005). Hygrothermal performance of buildings - Calculation and presentation of climatic data - Part 4: Hourly data for assessing the annual energy use for heating and cooling (EN ISO 15927-4).

European Commitee for Standardisation (2007). Building components and building elements - Thermal resistance and thermal transmittance - Calculation method (EN ISO 6946).

European Commitee for Standardisation (2009). Hygrothermal performance of buildings - Calculation and presentation of climatic data - Part 3: Calculation of a driving rain index for vertical surfaces from hourly wind and rain data (EN ISO 15927-3).

European Commitee for Standardisation (2007). Hygrothermal performance of building components and building elements - Assessment of moisture transfer by numerical simulation (EN 15026).

European Commitee for Standardisation (2012). Hygrothermal performance of building components and building elements - Internal surface temperature to avoid critical surface humidity and interstitial condensation - Calculation methods (EN ISO 13788).

European Union, Directive (EU) 2018/844 of the European Parliament and of the Council of 30 May 2018 (2018), Official Journal of the European Union (Directive 2018/844/EU)

Freudenberg, P., Ruisinger, U., Stöcker, E. (2017), Calibration of Hygrothermal Simulations by the Help of a Generic Optimization Tool, Energy Procedia 132, 405-410.

Havinga, L., Schellen, H. (2018), Applying internal insulation in post-war prefab housing: Understanding and mitigating the hygrothermal risks, Building and Environment 144, 631- 647.
Kalamees, T., Vinha, J., Kurnitski, J. (2006) Indoor Humidity Loads and Moisture Production in Lightweight Timber-frame Detached Houses, Journal of Building Physics 29, 219-246

Murano, G., Corrado, V., Dirutigliano, D. (2016), The new Italian climatic data and their effect in the calculation of the energy performance of buildings. Energy Procedia 101, 153-160.

Roberti, F., Filippi Oberegger, U., Gasparella, A. (2015), Calibrating historic building energy models to hourly indoor air and surface temperatures: Methodology and case study, Energy and Buildings 108, 236-243.

Rondoni, M., Santa, U., Klammsteiner, U., Demattio, M., Bancher, M., Told, A., Zelger, T. (2015), Proceedings form Building Simulation Applications BSA 2015, 4 6 February 2015.

Ruisinger, U., Grunewald, J. (2009), Feuchteatlas zur Vermeidung Planungsbedingter Feuchteschäden. Neue Beurteilungskriterien zur Bewertung innengedämter Konstruktionen, Institut für Bauklimatik, Technische Universität, Dresden, Germany.

Troi, A. (2011), Historic buildings and city centres, potential impact of conservation compatible energy refurbishment on climate protection and living conditions. Proceeding from Conference on Energy Management in Cultural Heritage, Dubrovnik, 6-8 April 2011.

Troi, A. and Bastian, Z. (2015). Energy Efficiency Solutions for Historical Buildings: A Handbook. Birkhäuser.

Vereecken, E. and Roels, S. (2013) Hygric performance of a massive masonry wall: How do the mortar joints influence the moisture flux?, Construction and Building Materials 41, 697-707.

W.T.A. Merkblatt 6-5 (2014), Interior insulation according to WTA II: evaluation of internal insulation systems with numerical design methods, Wissenschaftlich-Technische Arbeitsgemeinschaft für Bauwerkserhaltung und Denkmalpflege e.V, 2014.

Zhao, J., Grunewald, J., Ruisinger U., Feng S. (2017) Evaluation of capillary-active mineral insulation systems for interior retrofit solution, Building and Environment journal 115, 215-227. 